\title{
Efectos económicos de la aplicación de impuestos directos e indirectos a las PYMES en la provincia de Tungurahua periodo 2014 - 2017
}

Economic effects of the application of direct and indirect taxes to SMEs in the province of Tungurahua period $2014-2017$

Jonny Jesús Flores Guamán. ${ }^{1} \&$ Mario Patricio Padilla Martínez. ${ }^{2}$

DOI: https://doi.org/10.33262/visionariodigital.v3i3.606

\begin{abstract}
Companies are the engine of the country's economy through their economic activities they generate, employment and contribute to economic growth, especially the SMEs that are structured by organizations with greater capacity to adapt to technological changes and generate sources of employment and they become an important factor of income distribution policy to the middle and lower social strata. They are engines of economic development that contribute to the payment of taxes that act as instruments of the State to promote economic growth, and influence the levels of distribution of wealth. SMEs at the time of paying their taxes, direct and indirect depending on the economic activity they perform, the size, the amount of their income and their capital lack the basic knowledge on tax incentives and payment of taxes by $89 \%$, to know the reality that is generated. An investigation has been carried out on the impact of direct and indirect taxes on SMEs in the province of Tungurahua in the period 2014-2017, the objective for this study is to determine the economic effects of direct and indirect taxes on SMEs, through the analysis of theoretical sources, identifying the current economic situation through appropriate methodologies. The foundations and elements of discussion regarding taxes in SMEs from a historical perspective, to analyze the results
\end{abstract}

\footnotetext{
1 Universidad Técnica de Ambato, Facultad de Ciencias Administrativas Ambato, Ecuador, jflores6124@uta.edu.ec

2 Universidad Técnica de Ambato, Facultad de Ciencias Administrativas Ambato, Ecuador, mp.padilla@uta.edu.ec
} 
obtained with the survey applied knowing the sample of a finite population of 3151, to know about the type of activity and the diversification of the same in the primary, secondary and tertiary economic sector of the province being natural or legal persons obliged and not obliged to keep accounts, the results indicate that SMEs in the province of Tungurahua have a tax payment in a range between 500 to 5000 USD, where the most collected taxes are the (VAT) with a percentage of 100\%, the Tax and Advance to Income with $100 \%$, withholding to source with $68 \%$, VAT withholding with a percentage of $26 \%$ and the exit of foreign currency with $2 \%$, in the payment of fiscal taxes to the SRI, the items collected by the municipalities correspond: the property tax and municipal patents with a collection percentage of 100\%, additional SMEs with legal status tend to pay taxes to the Superintendence of Companies that amount over to 10\%. Fiscal and tax policies have affected SMEs over time with negative factors, because they promote inflation as the increase in the price of production which is reflected in the sale price of different products and services, offering little competitiveness in the market, closure of SMEs and as a result the dismissal of workers.

Keywords: SMEs; Direct Taxes; Indirect Taxes; Technology; Taxes.

\section{RESUMEN}

Las empresas son el motor de la economía del país a través de sus actividades económicas generan empleo y contribuyen al crecimiento económico, en especial las PYMES que están estructuradas por organizaciones con mayor capacidad para adaptarse a los cambios tecnológicos y generar fuentes de empleo, convirtiéndose en un factor importante de política de distribución de ingresos a los estratos sociales medio y bajo; son motores del desarrollo económico que aportan con el pago de impuestos los cuales actúan como instrumentos del Estado para promover el incremento económico, e influir en los niveles de distribución de la riqueza. Las PYMES al pagar sus impuestos, directos e indirectos dependiendo de la actividad económica que realice, el tamaño, el monto de sus ingresos y su capital carecen del conocimiento básico sobre los incentivos tributarios y el pago de impuestos, para conocer la realidad que se genera, se ha realizado una investigación sobre el impacto que genera los impuestos directos e indirectos en las PYMES en la provincia de Tungurahua en el periodo 2014 -2017, el 
objetivo para este estudio es determinar los efectos económicos que causan los impuestos directos e indirectos en las PYMES, mediante el análisis de fuentes teóricas, identificando la situación económica actual a través de metodologías adecuadas. Los fundamentos y elementos de discusión referentes a impuestos en las PYMES desde una perspectiva histórica, para analizar los resultados obtenidos con la encuesta aplicada conociendo la población finita de 3151, para saber sobre el tipo de actividad y la diversificación de las mismas en el sector económico primario, secundario y terciario de la provincia de Tungurahua como personas naturales o jurídicas obligadas y no obligadas a llevar contabilidad, los resultados indican que las PYMES en la provincia tienen un pago sobre impuestos en un rango entre 500 a 5000 USD, los impuestos más recaudados son el (IVA) con un porcentaje del 100\%, el Impuesto y Anticipo a la Renta con un $100 \%$, retención a la fuente con un $68 \%$, retención al IVA con un porcentaje del $26 \%$ y la salida de divisas con un 2\%; las recaudaciones de las municipalidades corresponden a: el Impuesto predial y Patentes Municipales con un porcentaje de recaudación del 100\%, adicional las PYMES con categoría jurídica tienden a pagar tributos a la Superintendencia de Compañías que asciende a un 10\%. Las políticas fiscales y tributarias han afectado a través del tiempo a las PYMES con factores negativos, ya que promueven la inflación como el aumento del precio de producción lo que refleja en el precio venta de los diferentes productos y servicios, ofreciendo poca competitividad en el mercado, cierre de las PYMES y como efecto el despido de los trabajadores.

Palabras Clave: PYMES, Impuestos Directos, Impuestos Indirectos, Tecnología, Tributos.

\section{INTRODUCCIÓN}

La empresa está definida como la unidad productiva económica - social y fundamental para la economía de un país, mediante el intercambio de productos o servicios, genera empleo y crecimiento económico, las mismas son un factor importante para el desarrollo y sostenibilidad económica de un país. Las empresas se clasifican según su tamaño en pequeñas, medianas y grandes, se le denomina de forma abreviada PYMES, últimamente se les ha sumado a estos tres tipos de empresas un cuarto, las microempresas, que también se incluyen en las 


\section{MIPYMES.}

Para el estudio abordaremos que las Pequeñas y Medianas Empresas (PYMES) juegan un papel de gran importancia dentro del desarrollo de toda economía debido a su relación e incidencia en la generación de empleo, y crecimiento económico. De esta forma las PYMES se relacionan directamente con el desarrollo económico en todas las regiones del país. Si bien al analizar los factores de crecimiento económico se identifican como responsables a las grandes empresas, en realidad los resultados indican que el crecimiento depende en buena medida del desempeño de sus PYMES. Desarrollar una PYME en Ecuador no es tarea sencilla es así como Ecuador ocupa la posición 114 de 190 en el ranking global Doing Business del Banco Mundial, 166 en el indicador de apertura de un negocio, 101 para obtención de un crédito y 137 para pago de impuestos (EKOS, 2017).

Según Banco Bilbao Vizcaya Argentaria BBVA, (2018) existen algunos criterios para La clasificación de las MIPYMES, como se observa en la figura1:

Figura 1. Criterios de clasificaciones las empresas

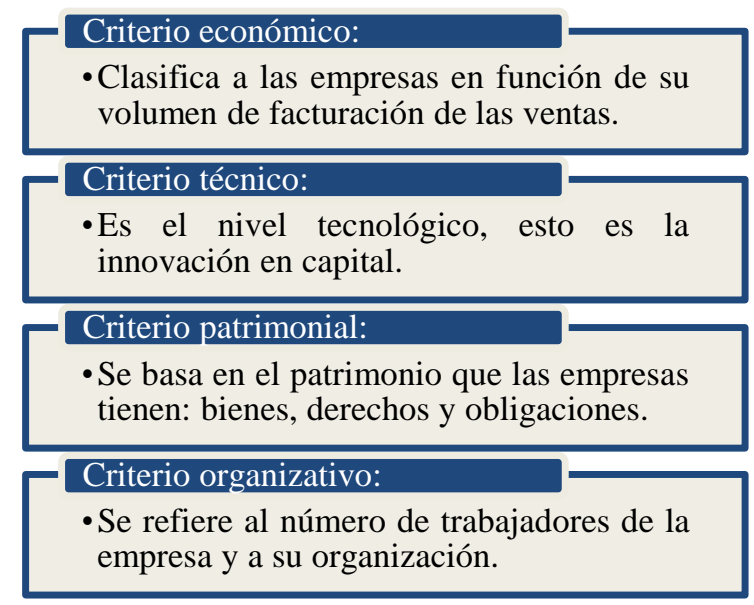

Fuente: (BBVA, 2018).

De acuerdo a la institución gubernamental: Instituto Nacional Ecuatoriano de Censos INEC (2017), clasifican a las empresas por el volumen de ventas anual (V) y el número de personas ocupadas (P) en las que se detalla en la siguiente tabla $\mathrm{N}^{\circ} 1$, las empresas se clasifican por diferentes características en las que destaca principalmente el volumen de las ventas anuales y los colaboradores que las conforman. 
Tabla 1. Clasificación de las empresas.

\begin{tabular}{lll}
\hline Tipo de empresa & $\begin{array}{l}\text { Volumen de ventas } \\
\text { Anuales }\end{array}$ & Personas \\
\hline Empresa grande & $\$ 5^{\prime} 000.001$ & 200 en adelante \\
\hline Mediana Empresa & $\$ 2^{\prime} 000.001$ a $\$ 5^{\prime} 000.000$ & 100 a 199 \\
\hline Pequeña Empresa & $\$ 100.001$ a $\$ 1^{\prime} 000.000$ & 10 a 49 \\
\hline microempresa & $<$ a $\$ 100.000$ & 1 a 9 \\
\hline
\end{tabular}

Fuente: (INEC, 2017).

La clasificación por su rama el INEC les incluye a las empresas en la actividad Clasificación Industrial Internacional Uniforme (CIIU, 2014), que tiene una estructura coherente y consistente de todas las actividades económicas que realizan las empresas, emitida por la Organización de Naciones Unidas (ONU), basada en un conjunto de conceptos, principios y normas de clasificación como podemos observar en la Tabla 2:

Tabla 2. Clasificación Industrial según CIIU

\begin{tabular}{llll}
\hline & & & Sección \\
\hline A & Agricultura & K & Construcción \\
\hline B & Minas y canteras & L & Inmobiliaria \\
\hline C & Manufacturas & M & Científico Técnico \\
\hline D & Suministro energías & N & Administrativo \\
\hline E & Distribución de agua & O & Administración publica \\
\hline F & Financieras & P & Enseñanza \\
\hline G & Comercio & $\mathbf{Q}$ & Sal \\
\hline H & Transporte & R & Arte \\
\hline I & Alojamiento & S & Otros servicios \\
\hline J & Información & & \\
\hline
\end{tabular}

Fuente: (INEC, 2017).

Las empresas en Ecuador están en relación con el sector económico donde es amplio y está dividido en: La agricultura, ganadería, silvicultura y pesca; Explotación de minas y canteras; Industrias manufactureras; Comercio; Construcción y servicios (INEC, 2017). El conjunto de empresas define la actividad y el conjunto de actividades definen al sector, con una buena gestión empresarial se demuestra el crecimiento de sus ventas; cuando crecen las ventas; también crecen el sector, hay un desarrollo sostenible en la provincia y al mismo tiempo en el país. (Padilla, Quispe, Rivera, Hernandez, \& Moreno, 2018). 
Las empresas son unidades productivas que contribuyen económicamente a la sociedad, mismas que generan fuentes de trabajo siendo un factor importante para la economía del país, dentro de la clasificación de las PYMES se encuentran las grandes, medianas y pequeñas empresas que se diferencian por su patrimonio, personas que la constituyen y los productos o servicios que producen.

Como podemos observar en la Figura 2 la economía ecuatoriana se sostiene principalmente por el sector comercio con el $36,13 \%$, y el sector de la agricultura y ganadería con un 11,10\%, nos muestra que las primeras 5 actividades económicas concentran el 72,35\% de empresas en el país.

Figura 2. Clasificación de las PYMES de acuerdo a sus actividades económica.

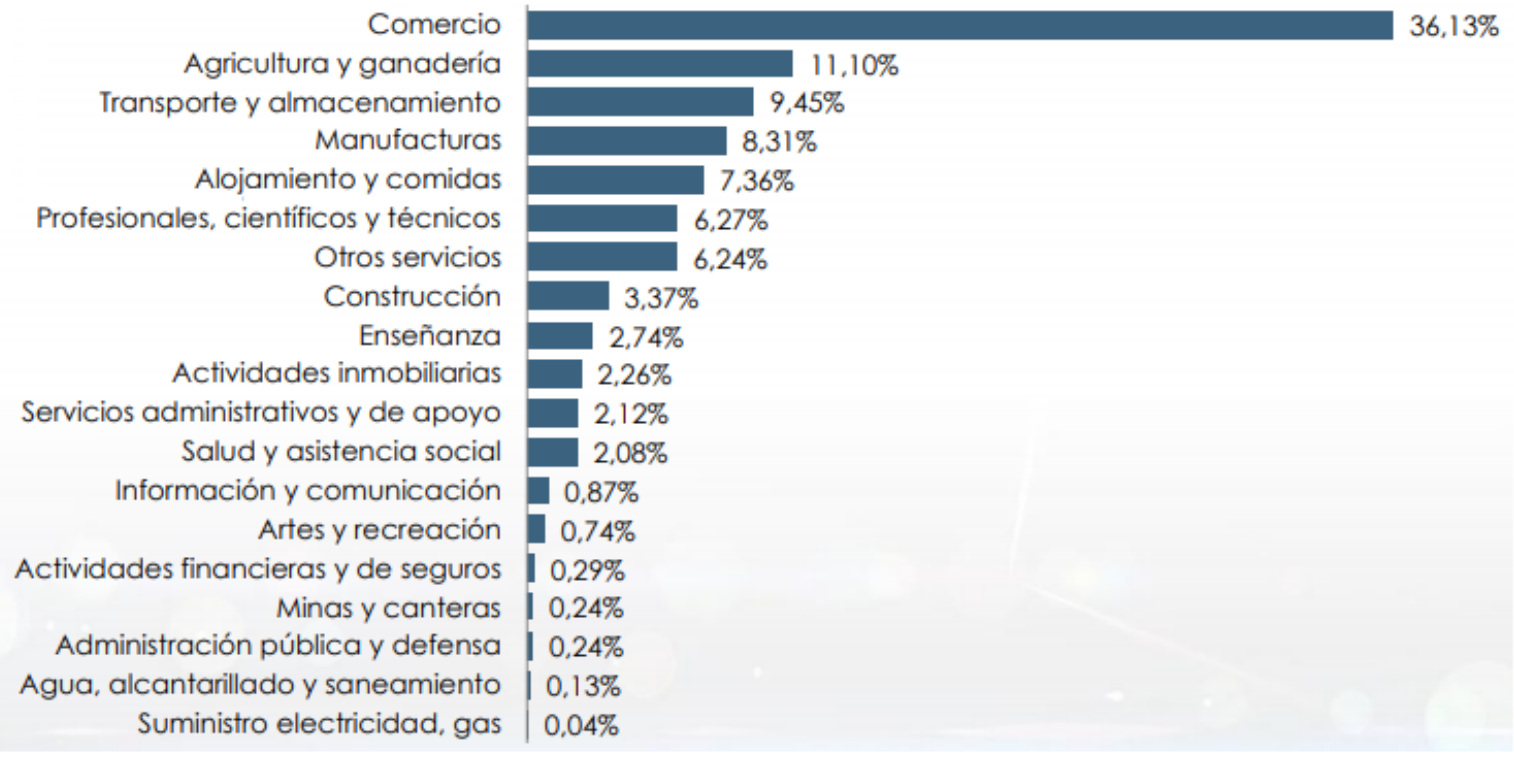

Fuente: (INEC, 2017).

La provincia de Tungurahua es un factor muy importante dentro las PYMES, debido a que se encuentra un gran número de ellas a sus alrededores con diferentes actividades económicas, como se puede observar en la figura 3 representa el número de actividades económicas existentes en la provincia de Tungurahua, se sostiene principalmente por el comercio al por mayor y menor con un porcentaje de $52,82 \%$ y en segundo lugar el sector de la industria manufacturera; ello determina que se produzcan diferentes relaciones con los impuestos y determina al organismo central el SRI como gestor tributario, contando con las potencialidades del talento humano y de su plataforma tecnológica, en donde se sustenta, no solamente en el pago voluntario, sino en el mejoramiento de los servicios y la observancia de los derechos de los ciudadanos/contribuyentes, sino también en el fortalecimiento del control y en la 
ampliación de la base tributaria (Servicio de Rentas Internas, 2015).

Figura 3. Clasificación de las PYMES de acuerdo a sus actividades económica en Tungurahua

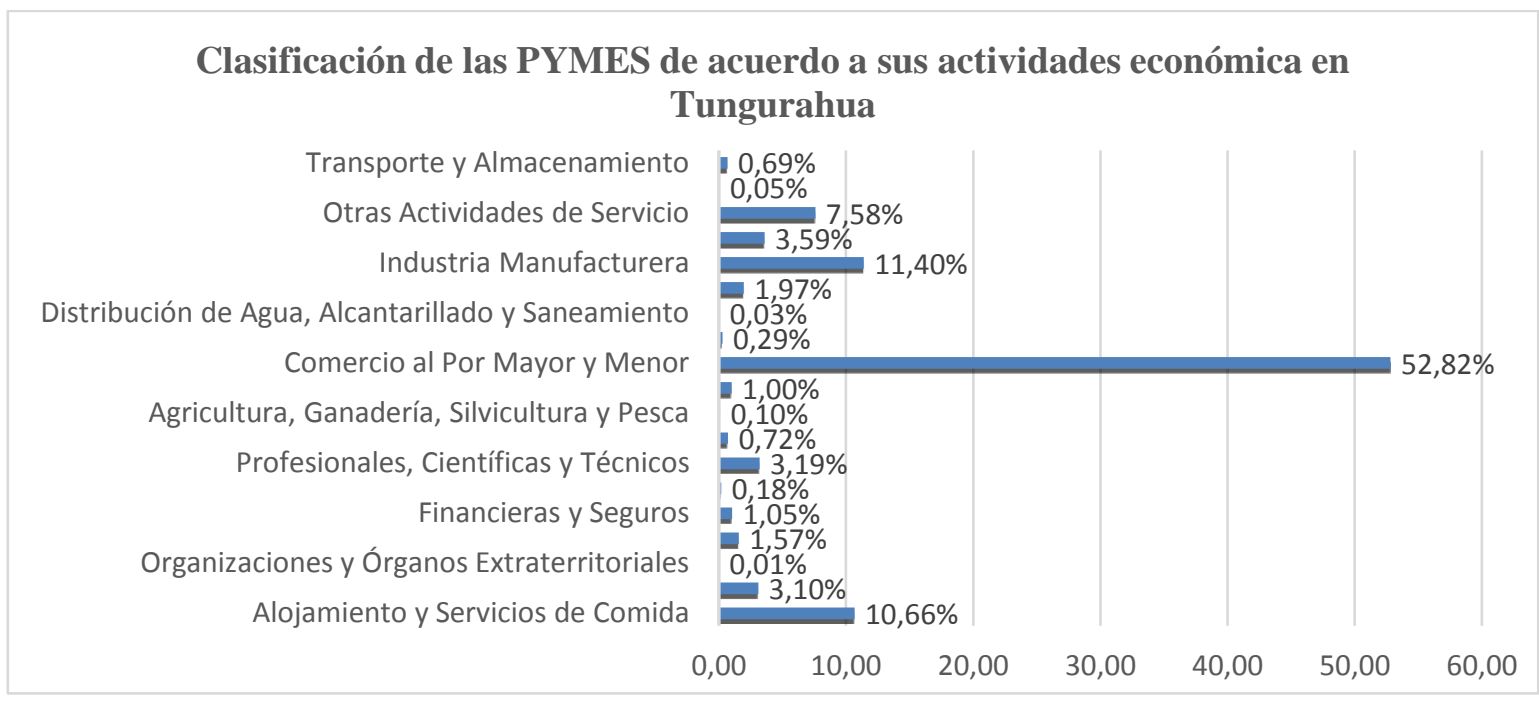

Fuente: (INEC, 2010).

La cultura tributaria con el pago de los tributos es un problema existente en varios países destacándose los que se encuentran en vías de desarrollo, por lo que no existe conciencia tributaria o la estructura del sistema tributario no es el correcta. El desconocimiento de las obligaciones tributarias que contrae una persona o sociedad al momento de realizar cualquier actividad económica conlleva a que se cometa evasiones en el pago de los tributos (Lopez, 2012). Los tributos en Ecuador se clasifican en dos tipos como se observa en la tabla 3.

Tabla 3 Tributos en Ecuador

\begin{tabular}{ll}
\hline \multicolumn{1}{c}{ Tipo } & Impuesto \\
\hline Impuestos sobre la renta, ganancias y activos & Impuesto a la Renta, Impuesto sobre Activos \\
& Totales, Contribuciones a las Entidades \\
& Gubernamentales Reguladoras, Impuesto a \\
& la Propiedad Urbana, Impuesto Especial al \\
& Capital Neto de Sociedades. \\
\hline Impuestos sobre transacciones & Impuesto al Valor Agregado 12\%, Impuesto \\
& a los Consumos Especiales, Impuesto a la \\
& Transferencia de Títulos de Propiedad de \\
& Bienes Raíces, Impuestos Aduaneros. \\
\hline
\end{tabular}

Fuente: Servicio de Rentas Internas, 2019

Los tributos en Ecuador son un factor importe para el desarrollo del país, sin embargo, los empresarios de sección pequeña y microempresa tienen menor información sobre los 
impuestos y obligaciones a pagar. El gobierno ecuatoriano crea medidas como la promulgación de leyes y reglamento administrados por entes reguladores como el Servicio de Rentas Internas con la denominación (SRI) para la recaudación y cumplimiento de las obligaciones. La problemática se enfoca en la falta de capacitación y desconocimiento de la cultura tributaria que conlleva a la evasión e incumplimiento de las obligaciones tributarias, afectando en gran medida a la sociedad ya que son factores que impulsan el crecimiento del país

En Tungurahua algunas PYMES siguen comportándose como si nada hubiese cambiado dentro del sistema de recaudación fiscal del SRI, pero son los de la realidad lo que ha hecho que las PYMES tengan en cuenta muchos otros factores, por qué los mercados ya no crecen en función de la oferta, y hay que luchar en mercados más competitivos y a veces poco recesivos interiormente, sin contar con los problemas de competencia de empresas foráneas (Domínguez, 2014).

Por lo tanto la cultura tributaria indica que es un conjunto de valores, conocimientos y actitudes compartidos por los miembros de una sociedad respecto a la tributación y la observancia de las leyes que la rigen, esto se traduce en una conducta manifestada en el cumplimiento permanente de los deberes tributarios con base en la razón, la confianza, la afirmación de los valores de ética personal, respeto a la ley, responsabilidad ciudadana y solidaridad social, tanto de los contribuyentes, como de los funcionarios de las diferentes administraciones tributarias (Herrero, 2015), para lo cual se toman los siguientes conceptos:

\section{Tecnología en la recaudación fiscal}

Las facilidades o recursos existentes en la actualidad como son las TICS permiten ofrecer al contribuyente un servicio de calidad, el conocimiento de normas claras y de fácil comprensión e imponer sanciones creíbles y aplicables, sin eludir la particularidad de los diversos sectores económicos existentes y el grado de dificultad tecnológica en el sector productivo.

En los últimos años el ente administrativo tributario el SRI han optado por el uso de la tecnología como un aliado contra la evasión y elusión tributaria, así como poder aumentar el cumplimiento de obligaciones de los contribuyentes con los avances tecnológicos, logrando un mayor control por parte de la entidad encargada de la recaudación de tributos, todo esto da como resultado la reducción de costos de gestión y tiempo, lo que permite una mayor confiabilidad en datos de los contribuyentes. (Prado, 2016)

Las aplicaciones tecnológicas han sido implementadas hace algunos años atrás en otros países 
vecinos, nuestro país también ha avanzado siguiendo estas figuras tributarias, incluso la inserción de las técnicas o aplicaciones tecnológicas en materia tributaria ha dado lugar a la facturación electrónica, electronic taxation (impuesto electrónico) electronic goverment (gobierno electrónico). (Prado, 2016)

El sistema tributario ecuatoriano se ha venido fortaleciendo progresivamente en los últimos años, este fortalecimiento se alcanzado a través de mecanismos tecnológicos implementados, sin desmerecer a las leyes, reformas y política tributaria ejecutadas por el Gobierno, esto con la finalidad de reducir la evasión fiscal o identificar los errores de los contribuyentes en las obligaciones tributarias reportadas a la Administración Tributaria siendo así que las recaudaciones tributaria en año 2014 superó lo esperado cumpliendo en un 104\% de lo estimado y el año 2015 alcanzó el 95\% de lo presupuestado. (Faustos, 2016)

\section{Entorno fiscal}

El entorno fiscal son efectos directos e indirectos, estos efectos se refieren a las políticas que tiene un país y su incidencia en los cambios que realicen en la gestión general de la empresa, factores económicos, factores socioculturales, político-legales, tecnológicos y ecológicos, los mismos que pueden tener efectos de aspecto positivo como negativo, es interesante conocer bien estas interrelaciones, porque pueden aportar a la empresa oportunidades de negocio en otras áreas geográficas, tanto del propio país como de otras comunidades internacionales. (Velez, 2014)

La gestión Empresarial, está relacionada con su entorno, según Grinvalds, (2018) se puede definir como la habilidad que tienen los líderes de organizar, controlar y dirigir a un grupo de personas dentro de una organización para poder alcanzar un objetivo propuesto a través de distintas estrategias, los pilares para una buena gestión empresarial está basada en 4 factores cambiantes:

La Planificación, es donde se establece muy bien las metas y cada una de las actividades y estrategias que vas a seguir para llegar a tus objetivos empresariales, la Organización es tan importante que puede marcar el éxito o fracaso de un negocio. Empieza desde ya a definir, asignar y coordinar cada una de las actividades que se van a llevar a cabo, quién las realizará, en qué tiempo y cómo lo hará, la dirección, esta función es para líderes de verdad que impulsen 
y motiven a cada uno de los miembros de la organización, el personal de dirección debe mantener una serie de cualidades necesarias en el trato hacia los demás como el asertividad y la empatía; Control, coordinar y supervisar el trabajo que se va realizando, el control se convierte al final en la herramienta necesaria para establecer medidas a corto y largo plazo, sin poner en riesgo la situación de la empresa.

\section{Los impuestos como tributos fiscales}

Los impuestos juegan un papel muy importante en el presupuesto de un Estado. Desde la antigüedad, los tributos han permitido el desarrollo de los pueblos y gobiernos. Sin embargo, según Keynes en su obra de "La Teoría General del Empleo, Interés y el Dinero" (1936) estableció que un aumento en la carga tributaria tendrá como resultado una disminución en la producción y el consumo. Los impuestos están dados como uno de los elementos importantes que cuenta un estado para el desarrollo económico ya que través de los mismos puede incidir en el grado de adjudicación del ingreso entre la población sea a través de un determinado nivel de tributación entre los distintos estratos o mediante el gasto social, lo que depende del nivel de recaudación obtenida (Játiva \& Ortega, 2016).

\section{La recaudación tributaria en las PYMES}

Las estrategias de control o fiscalización tributaria son fundamentales en dicha lucha, resulta claro que el esfuerzo por controlar el cumplimiento tributario y generar un riesgo creíble ante el incumplimiento no basta por sí solo para vencer las prácticas de evasión (Siñani, 2012)., de acuerdo a la teoría económica, la recaudación fiscal está relacionada con el tipo impositivo o carga fiscal, según esta, la función que denota los ingresos fiscales forma una gráfica de tipo parabólico, la misma que posee un máximo entre 0 y 1, es decir, la función posee una parte creciente y una decreciente en ese intervalo (Beltrán, 2014). Los individuos informados sobre lo político tienden a mostrar mayor información sobre lo tributario. La calidad del conocimiento sobre los impuestos autoriza a pensar que se trata especialmente del resultado de la transacción tributaria, donde el contribuyente sabe lo que paga y reconoce las razones del pago. Por otro lado, los ámbitos institucionales particulares no son transparentes, con la excepción del vínculo municipio-impuesto del territorio, que constituye una relación entre 
impuesto-institución que posiblemente es relevante en la ponderación del uso de los recursos y su efecto en la legitimación del sistema institucional (Onofre, Aguirre, \& Murillo, 2017).

La presión fiscal en la recaudación tributaria logra optimizar la recaudación fiscal. En consecuencia, las medidas del Estado no deberían de generar un nivel de presión fiscal superior a la tasa óptima, puesto que caso contrario la recaudación fiscal sería inferior al máximo posible (Vidal, Caraguay, \& Salcedo, 2017); los principios constitucionales tributarios existentes se ha cumplido a cabalidad, por lo que se logra la eficiencia en recaudación de impuestos directos e indirectos, los cuales han aumentado gradualmente en los últimos años esto demuestra el efecto de las nuevas políticas tributarias implementadas actualmente son de gran ayuda para el estado.

Objetivo general: Determinar los efectos económicos por la aplicación de impuestos directos e indirectos a las PYMES en la provincia de Tungurahua periodo 2014 - 2017; Objetivos específicos: Analizar las principales fuentes de información teóricas con relación de las PYMES y los impuestos; Indicar la situación económica actual de la PYMES en el País.; Desarrollar la metodología adecuada para la aplicación de los impuestos en las PYMES con la discusión de los resultados obtenidos.

El presente trabajo tiene como finalidad determinar el impacto económico que se generó en las PYMES de la provincia de Tungurahua por el pago de Impuestos directos (Impuesto a la Renta, Impuesto a los consumos especiales, Impuesto Predial, Impuesto sobre activos totales, Impuesto a la propiedad de vehículos) e Impuestos indirectos (Impuesto al valor agregado) durante el período 2014 - 2017, con el fin de definir el efecto positivo o negativo que causan sobre la aparición, crecimiento y expansión de las PYMES.

Las PYMES además de elegir su actividad a desarrollar deben conocer los diferentes impuestos a pagar, los mismos que varían de acuerdo a la forma jurídica, actividad comercial, tamaño y monto de facturación, actualmente se necesita tanto un material bibliográfico como un documento que sirva como base técnica para inicio de nuevas y más profundas investigaciones acerca de la realidad de las PYMES en la provincia de Tungurahua en cuanto a los efectos positivos o negativos en su crecimiento por el pago de impuestos directos e indirectos. Por otra parte, al conocer esta realidad se podrá identificar cual es el impacto económico que las PYMES tienen y al mismo tiempo conocer sobre las ventajas que la gestión empresarial, 
relacionado al desarrollo o no de las PYMES con el Gobierno de turno en la provincia a través de las leyes y reformas que contiene el código de la productividad favorece al desempeño y productividad de este sector.

\section{METODOLOGIA}

Para alcanzar el propósito central planteado la investigación se fundamenta en un paradigma critico propositivo, se enfoca y desarrolla bajo la modalidad cualitativo-cuantitativo, al ser cualitativo se refiere a los detalles y descripciones de los fenómenos que ocurren en el problema, es decir las deficientes bases técnicas con las obligaciones tributarias por parte de las PYMES ya que se encuentran en constantes cambios, tanto legales como características propias de las mismas y existe un desconocimiento de los tributos a pagar provocando factores negativos como la evasión de dichos tributos, al ser cuantitativo se refiere a la objetividad como una manera de alcanzar el conocimiento, utilizando la medición exhaustiva y controlada, buscando la certeza del mismo, se utiliza una estrategia deductiva, basándose en la investigación bibliográfica y documental con procedimientos científicos, leyes, libros, revistas, e información oficial afines con los impuestos.

Al mencionar que es de carácter exploratorio ya que ayuda a examinar el tema de este estudio, aplicando un cuestionario tipo encuesta validado por especialistas en el tema sobre impuestos, el cual consta de 12 preguntas cerradas en escala de likert que estarán dirigidas a empresarios, administradores y contadores que tengan el conocimiento acerca del pago de impuestos de las PYMES donde se realizara el levantamiento de información, posteriormente se analizó los resultados obtenidos formando un conjunto de procedimientos que tienen como objetivo la producción de un meta-texto, de manera complementaria es de gran importancia entender sobre los impuestos directos e indirectos conociendo la recaudación de impuestos y su incidencia en las PYMES de la provincia de Tungurahua.

La población para este estudio fueron las PYMES en la provincia de Tungurahua, un total de 3151 cifra tomada del INEC (2017), aplicando la formula predeterminada de población finita donde se obtuvo una muestra de 343, mismas han sido indagadas con técnica de investigación e instrumentos como la encuesta, los datos serán procesados en el programa estadístico 
"SPSS", mediante estos resultados obtenidos se realiza una interpretación de dicha información.

La prueba estadística que se aplica es la correlación de Spearman, es una medida de la relación lineal entre dos variables aleatorias cuantitativas. A diferencia de la covarianza, la correlación de Pearson es independiente de la escala de medida de las variables. De manera menos formal, podemos definir el coeficiente de correlación de Pearson como un índice que puede utilizarse para medir el grado de relación de dos variables siempre y cuando ambas sean cuantitativas.

\section{RESULTADOS}

Figura 4. Actividad de las PYMES

\section{1. ¿A qué tipo de actividad se dedica como PYMES?}

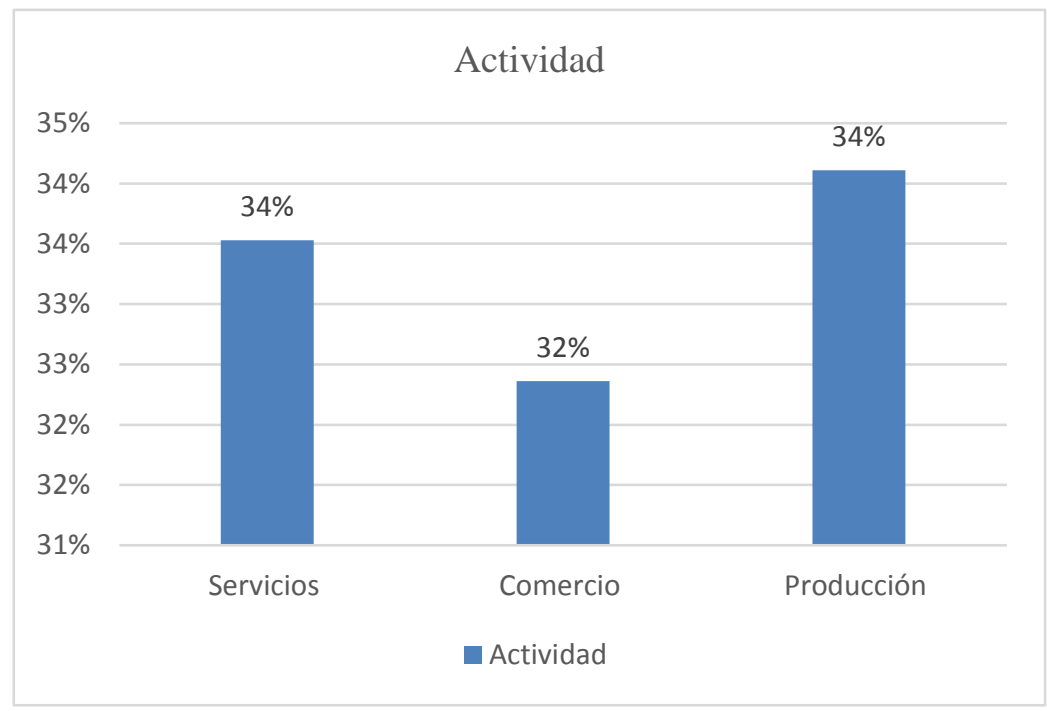

Elaborado por: Grupo de trabajo.

\section{Análisis:}

Las PYMES son indispensables para el crecimiento de toda economía de un país, según los datos obtenidos sobre la actividad que se dedican las PYMES encuestadas en la provincia de Tungurahua el 34\% son de producción, que se dedican a la fabricación de productos a través de materia prima, las de servicios, cuya actividad principal es de ofrecer servicio (intangible) y con un $32 \%$ las PYMES encuestadas fueron de comercio con un $32 \%$, las que se dedican a la compra y venta de materias primas o productos terminados. 
Figura 5. Las PYMES están obligadas a llevar contabilidad.

\section{2. ¿La PYMES donde usted labora está obligada a llevar contabilidad?}

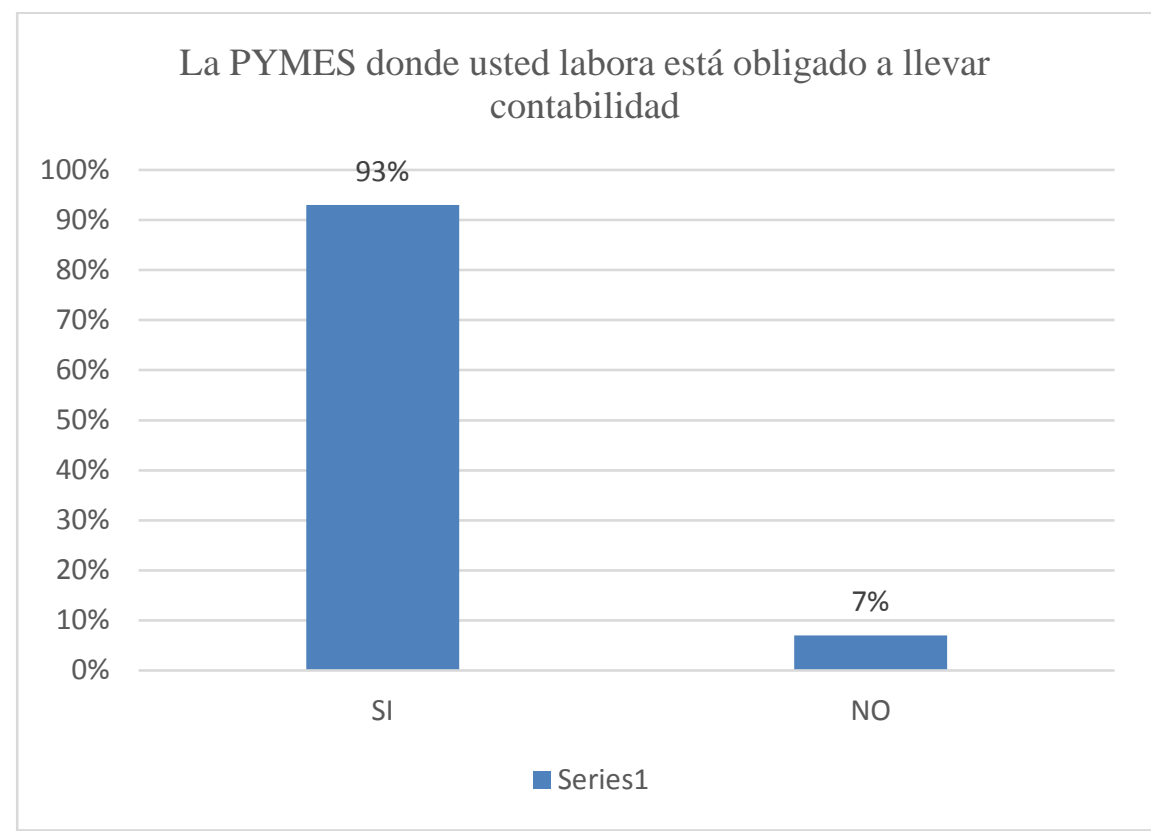

Elaborado por: Grupo de trabajo.

\section{Análisis:}

Las personas naturales, incluso cuando desarrollen actividades agrícolas, pecuarias, forestales o similares, profesionales, comisionista, artesanos, agentes, representantes y demás trabajadores autónomos de acuerdo a lo establecido en el Art. 19 de la ley Organiza de Régimen Tributario Interno, deben llevar contabilidad cuando: operen con un capital propio superior a 180.000,00 USD, sus ingresos totales sean superiores a 300.0000,00 USD y cuyos costos y gastos anuales imputables a la actividad económica, del ejercicio fiscal inmediato anterior hayan sido superiores a 240.000,00 USD. Las PYMES encuestadas en la provincia de Tungurahua se dedujo que de las 343 encuestadas un 93\% de las mismas llevan contabilidad, mientras el otro $7 \%$ informaron que no llevan contabilidad. 
Figura 6. Tipo de impuesto de las PYMES.

\section{3. ¿Qué tipo de impuesto declara las PYMES?}

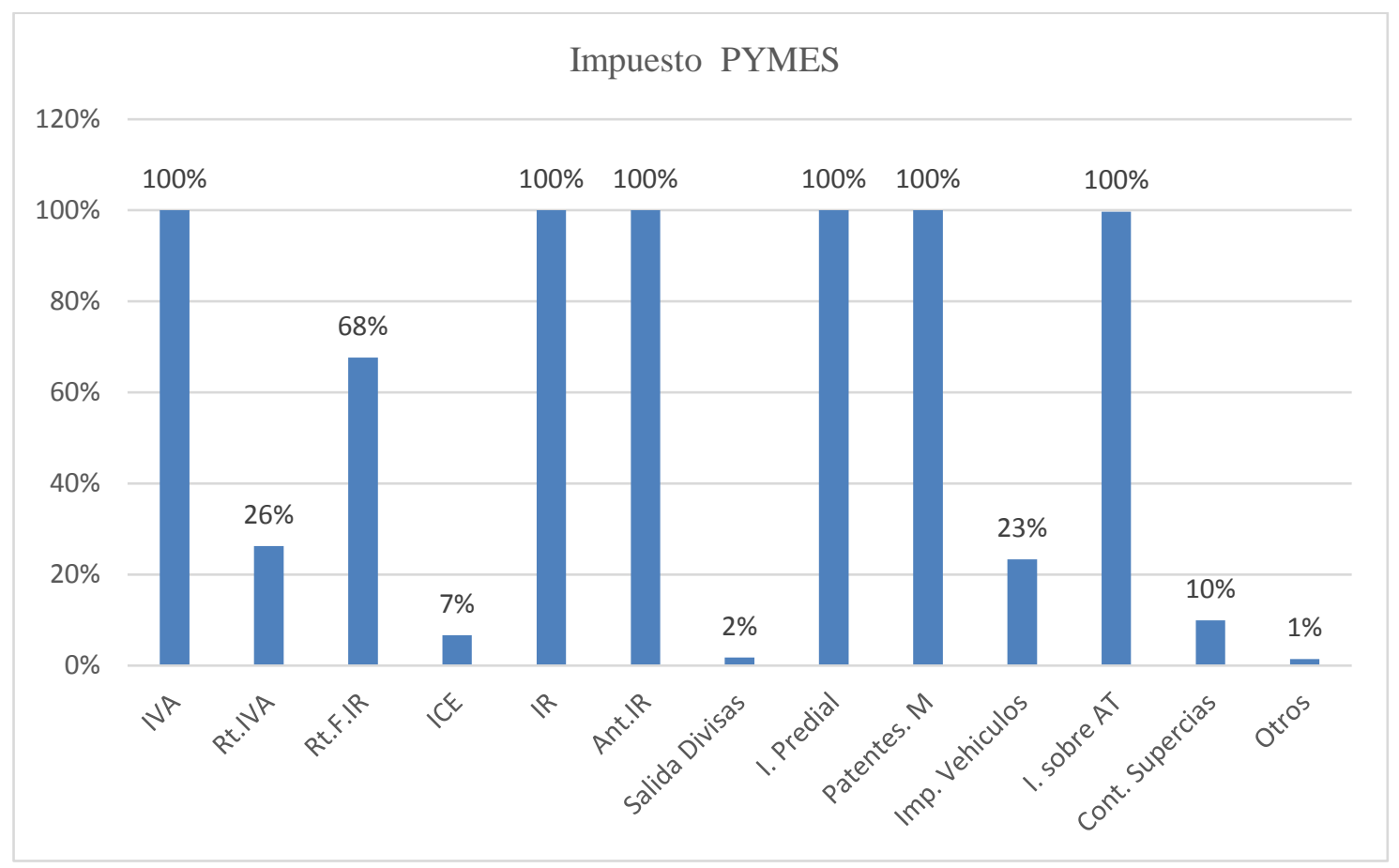

Elaborado por: Grupo de trabajo.

\section{Análisis:}

Los datos obtenidos sobre el tipo de impuestos directos que gravan directamente los ingresos e impuestos indirectos quienes gravan directamente el consumo de los contribuyentes, los que impuestos que presentan las PYMES son: el Impuesto al valor agregado (IVA) 100\%, Impuesto a la Renta 100\%, Anticipo Impuesto a la Renta 100\%, Impuestos sobre activos totales 100\%, Retenciones a la Fuente IR 68\%, Retención IVA 26\%, Impuesto a vehículos 23\%, Impuestos a consumos especiales (ICE) 7\%, Salida de Divisas 2\%, Contribución a la SUPERCIAS 10\%, en donde el organismo de control es el Servicio de Rentas Internas (SRI), es el mayor recaudador de impuestos, adicional existe otros entes de recaudación como son algunos Ministerios y Municipalidades con la recaudación del Impuesto predial con el 100\% y las Patentes Municipales con un $100 \%$, Otros tipo de impuestos con recaudación del 1\%, que son de menor grado. 
Figura 7. Organizaciones de control de las PYMES.

4. ¿Cuáles son los organismos de control para el funcionamiento de la PYMES?

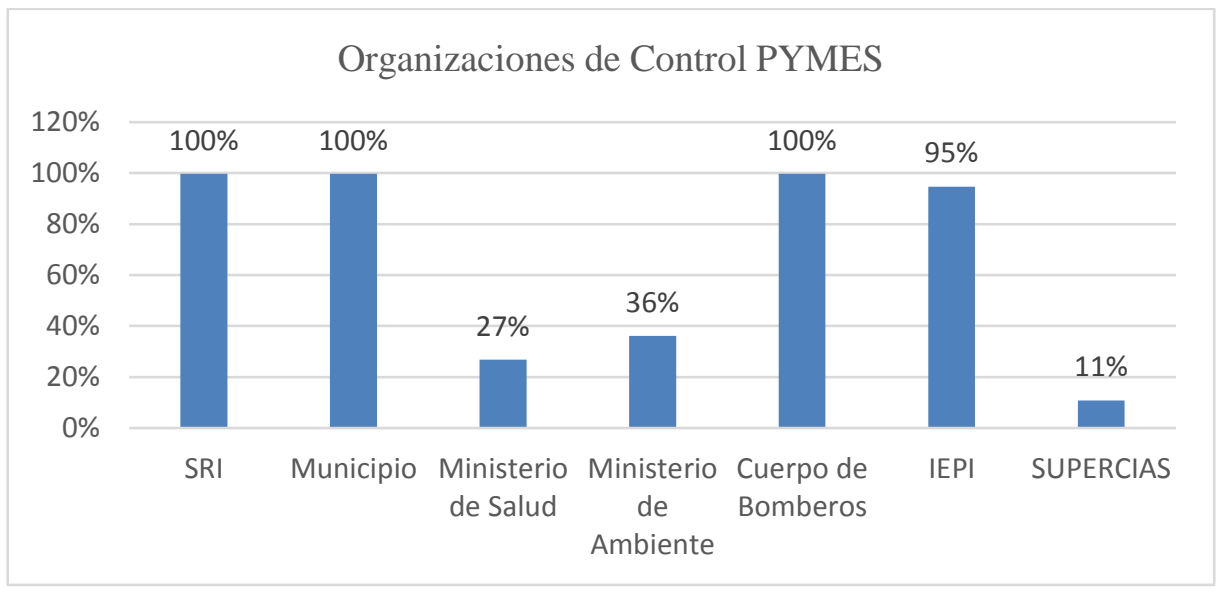

Elaborado por: Grupo de trabajo.

\section{Análisis:}

Las principales organizaciones de control para el correcto funcionamiento de las PYMES por la actividad son el (SRI) con un valor porcentual de 100\%, Cuerpo de Bomberos 100\%, Municipio100\%, (IEPI) 95\%, Ministerio de Ambiente 36\%, Ministerio de Salud 27\%, y SUPERCIAS con un $11 \%$.

Figura 8. Impuestos directos anuales PYMES

5. ¿Cuál es el monto aproximado que la PYMES paga por sus impuestos directos de forma anual?

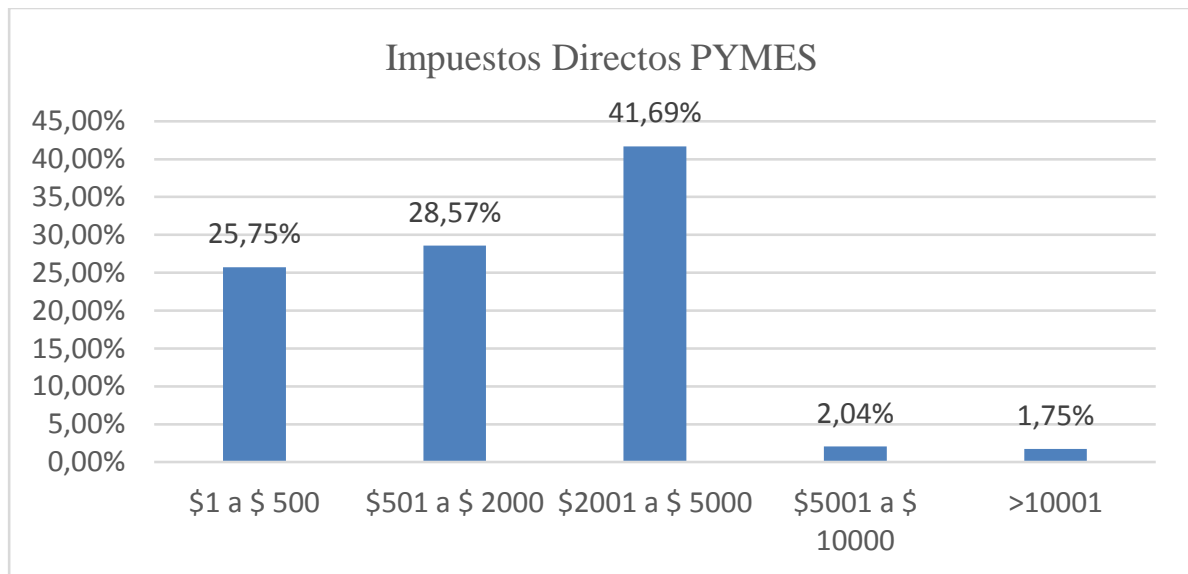

Elaborado por: Grupo de trabajo 


\section{Análisis:}

El aporte anual de las PYMES en los impuestos directos mayormente son $41.69 \%$ en el rango de $\$ 2001$ a $\$ 5000$, de $\$ 501$ a $\$ 2000$ un porcentaje acumulado de $28.57 \%$, \$1 a \$ 500 un valor porcentual de $25.954 \%$, $\$ 5001$ a $\$ 10000$ un resultado de $2.04 \%$ y finalmente el $1.75 \%$ de recaudaciones mayores a $\$ 10001$.

Figura 9. Factores negativos PYMES.

6. Las políticas fiscales y tributarias han afectado a la PYMES ocasionando factores negativos como:

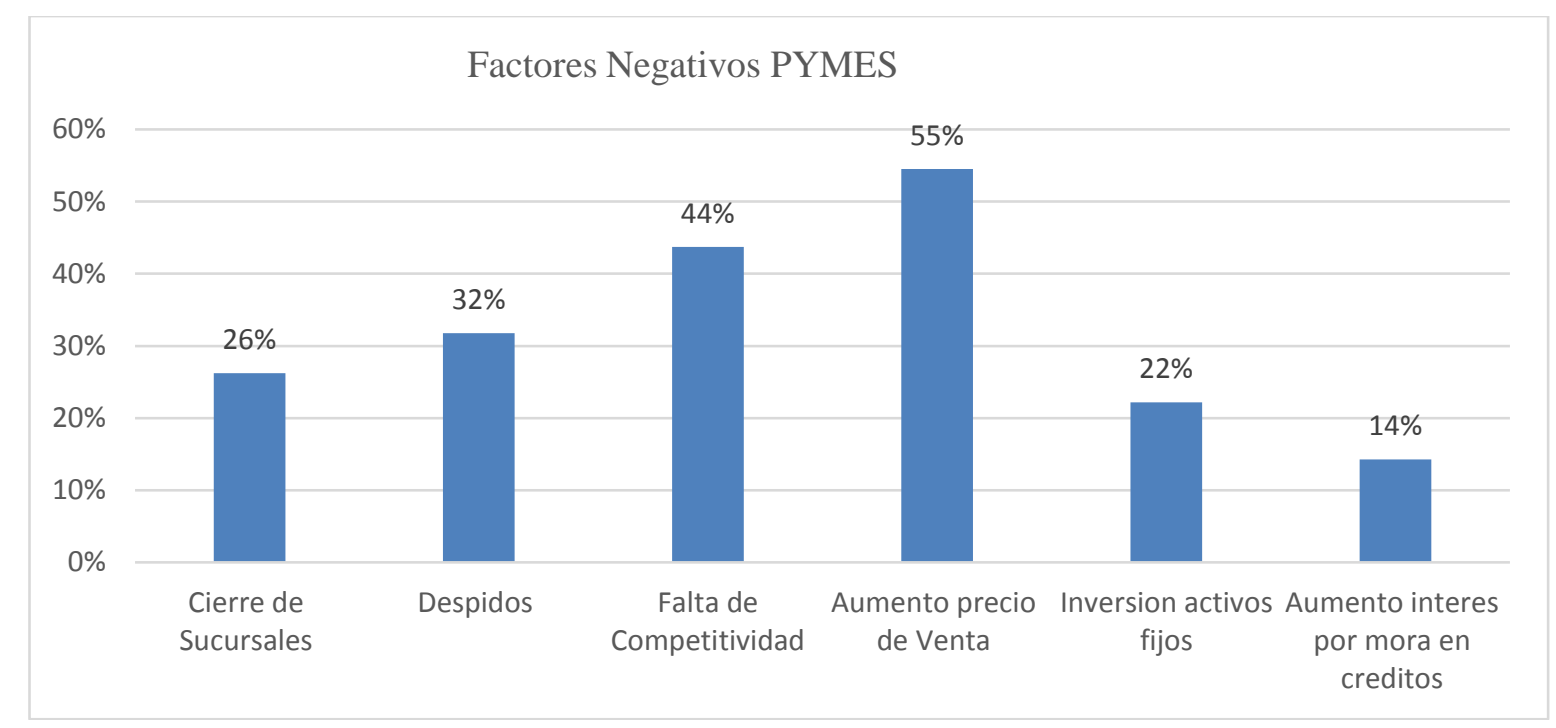

Elaborado por: Grupo de trabajo.

\section{Análisis:}

Las políticas fiscales y tributarias han afectado a través del tiempo a las PYMES ocasionando factores negativos como: El aumento de precio de venta de los diferentes servicios y productos con un $55 \%$, falta de competitividad con un $44 \%$, despidos de personal con un $32 \%$, cierre de sucursales con un $26 \%$, inversiones en activos fijos con un $22 \%$, y un aumento de interés por mora en créditos con un $14 \%$. 
Figura 10. Medidas o incentivos tributarios para la creación de nuevas PYMES en Ecuador.

7. ¿Conoce usted algunas medidas o incentivos tributarios que presta el Estado Ecuatoriano en la creación de nuevas PYMES?

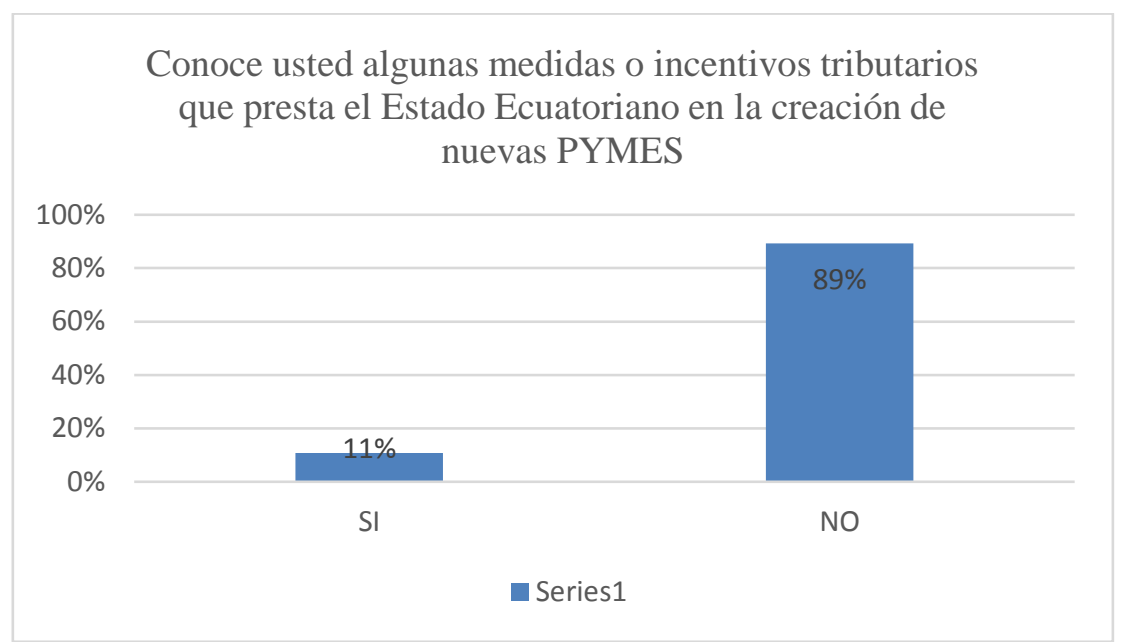

Elaborado por: Grupo de trabajo.

\section{Análisis:}

Según los datos obtenidos a partir de las 343 PYMES encuestadas refleja que existe un porcentaje de un $11 \%$ de la población ratifica que conoce de medidas o incentivos tributarios que presta el Estado Ecuatoriano en la creación de nuevas PYMES, por otro lado, un 89\% ratifica el desconocimiento de medias o incentivos propuestas por el Estado ecuatoriano.

\section{DISCUSIÓN}

Los ítems presentados en las personas encuestadas para conocer sobre el tipo de actividad a la que se dedican las PYMES, su diversificación en Tungurahua se divide en tres grupos según su actividad económica y son primarias ( dedicadas a obtener recursos naturales o materia prima), secundarias (dedicadas a transformar materia prima o bienes elaborados) y terciarias (dedicadas a la prestación servicios) todas las cuales dinamizan la economía generando plazas de empleo en la provincia, considerando la personas naturales y jurídicas obligadas y no obligadas a llevar contabilidad, las cuales, como se puede observar en el grafico N. ${ }^{\circ} 11$, de las 343 PYMES encuestadas declaran al SRI el pago del IVA, Impuesto a la renta, Anticipo al impuesto a la renta, Impuesto sobre activos totales y en un menor porcentaje lo que es Retención al Iva, Retención a la fuente, ICE y Salida de divisas, referente a los otros entes de recaudación como son las SUPERCIAS, con una recaudación por debajo del 10\%, 
municipalidades con un $100 \%$ y ministerios con el $1 \%$.

Figura 11. Mayores impuestos que pagan las PYMES

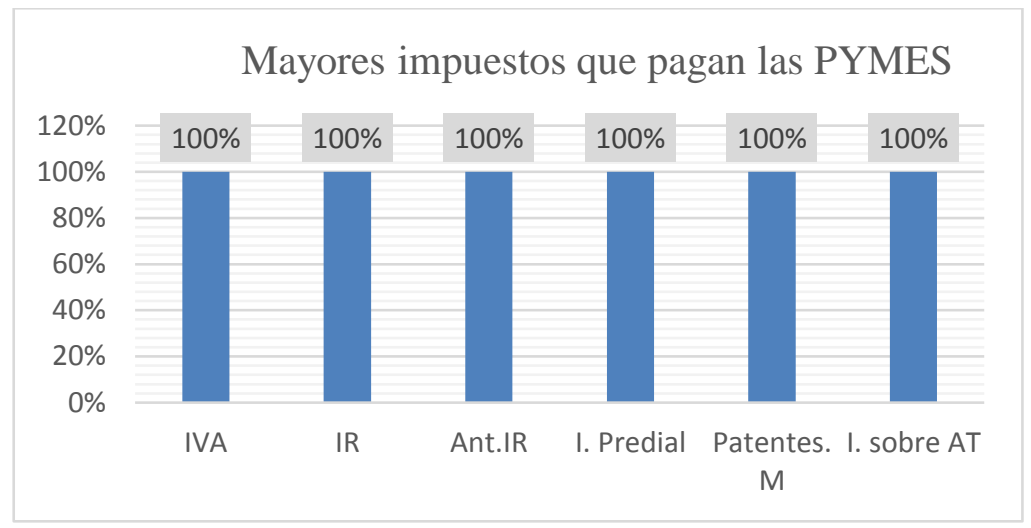

Elaborado por: Grupo de trabajo

Las PYMES desembolsan un monto aproximado de entre 2001\$ Y 5000\$ de forma anual por concepto de impuestos los más recaudados son el Impuesto al valor agregado (IVA), el Impuesto a la Renta, Anticipo Impuesto a la Renta, el Impuesto predial, Patentes Municipales, Impuestos sobre activos totales, en donde las PYMES deben poner mucho énfasis para su proyección de gastos ya que estos impuestos tienen efectos de percusión ya que afecta de forma directa a los ingresos, cabe recalcar que si la PYMES conlleva una buena organización financiera no tendrá efectos colaterales graves ya que en sus proyecciones deberían constar y tener predeterminada cierta cantidad para el pago de los impuestos directos.

Los datos obtenidos sobre el tipo de impuestos indirectos como lo menciona Trecet, (2015) "pueden ser de dos tipos: Multifásicos cuando el impuesto se grava en la compra y venta de los productos, y Monofásicos este se da cuando se grava solo una etapa del proceso"; los impuestos directos "gravan al ingreso, la riqueza, el capital o el patrimonio y que afectan en forma directa al sujeto del impuesto" 
Figura 12. Entes de control y recaudación de impuestos

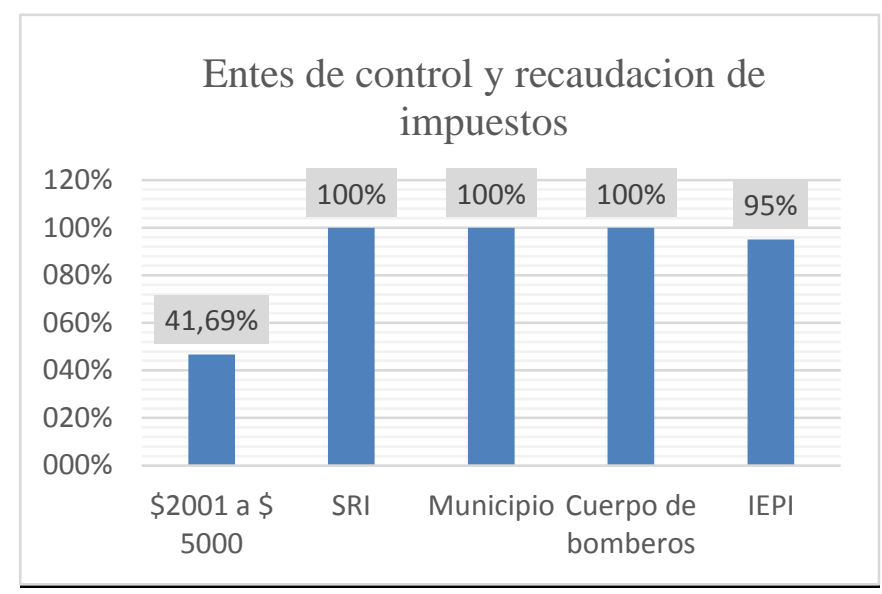

Elaborado por: Grupo de trabajo

El estado ecuatoriano ha creado diferentes entes de control y recaudación de impuestos para las PYMES entre los cuales está el SRI como principal recaudador de impuestos, los Municipios, Ministerios los cuales también se encargan de la recaudación atreves de permisos de funcionamiento, SUPERCIAS y el Instituto Ecuatoriano de Propiedad Intelectual (IEPI), tomando en cuenta que son diferentes las recaudaciones dependiendo de su tamaño, monto de facturación y actividad que realiza las PYMES, como se observa en el grafico N. ${ }^{\circ} 12$ el mayor ente control para las PYMES encuestadas en la provincia de Tungurahua.

Las políticas fiscales y tributarias según el autor Samuelson (2016) son "el presupuesto del Estado, y sus componentes, el gasto público y los impuestos, como variables de control para asegurar y mantener la estabilidad económica". Estas políticas han afectado a través del tiempo a las PYMES ocasionando factores negativos dentro de las empresas ya que varios impuestos promueven la inflación como el aumento del precio de producción lo cual se refleja en el precio venta de los diferentes productos y servicios, ofreciendo poca competitividad en el mercado, cierre de empresas y como efecto el despido de los trabajadores.

Según Tapia, (2018) en nuestro país existen diferentes medidas e incentivos para la creación de nuevas PYMES, en donde son desconocidas por muchos administradores o propietarios de las PYMES en Tungurahua, estos incentivos tributarios plantean exonerar desde 3 a 8 años dependiendo del caso el pago del impuesto a la renta para las PYMES que se creen o que 
realicen nuevas inversiones en el país, también se otorga la eliminación del anticipo al impuesto mínimo y la eliminación gradual desde el 2019 del impuesto a la salida de divisas, adicional se otorga facilidades para el acceso de créditos para la creación o ampliación de nuevas PYMES.

\section{CONCLUSION}

1. En efecto de percusión e incidencia de los impuesto directos e indirectos de las PYMES dentro de la legislación ecuatoriana refiere efectos positivos y negativos, ya que son rubros que aportan significativamente para el desarrollo del estado ecuatoriano sobre la asignación de recursos y la distribución de la renta y riqueza, sin embargo el exceso de los mismos se ve reflejado en el desarrollo mínimo de las PYMES; los impuestos que más toman en cuenta las PYMES en sus declaraciones son los que administra el Servicio de Rentas Internas (SRI) como es el impuesto al Valor Agregado (SRI), el Impuesto a la renta con las retenciones, en la provincia de Tungurahua es uno de los mayores entes de aportación ya que posee numerosas PYMES con un promedio según su actividad económica con un $34 \%$ productoras, $34 \%$ de servicios y $32 \%$ de comercio, con sus diferentes actividades.

2. El personal que administra la gran mayoría de las PYMES no posee una cultura tributaria y al mismo tiempo desconocen sobre las diferentes medidas o incentivos tributarios que presta el Estado ecuatoriano a las PYMES antiguas y nuevas, esto se debe que las entidades recaudadoras como el SRI deberían proporcionar más información no solo en la institución sino también en campo sobre la cultura tributaria existente y las diferentes ventajas que ofrece, la entidad recaudadora no lo toma como prioridad dar información de campo sobre los beneficios tributarios existentes para la creación de nuevas PYMES ya que se encuentran concentrados en su trabajo principal el cual es de la recaudación de los impuestos.

3. Se pudo analizar los diferentes puntos de vista del entorno fiscal a los cuales están sometidos las pequeñas, medianas y grandes empresas, (PYMES) mediante la metodología adecuada y el instrumento de la encuesta dirigida para empresarios, administradores y contadores en las PYMES, se pudo identificar la situación económica no es satisfactoria para los empresarios debido a que son recursos que podrían emplear para el desarrollo y mejora de sus activos y colaboradores, muchas veces no logran cumplir sus objetivos a largo plazo contra produciendo efectos negativos para la 
empresa y la sociedad debido a las políticas fiscales y tributarias con el incremento en el costo de la materia prima importada, aumento en el costo de producción, aumento en el precio de venta de servicios y productos ocasionando una disminución en la demanda, en las que muchas de las veces las PYMES no cumplen a tiempo con sus obligaciones lo cual genera despido de colaboradores e incluso cierre de empresas y sucursales afectando la economía de varias familias vinculadas.

\section{REFERENCIAS}

Agencia Tributaria Española. (12 de 11 de 2005). ¿Desde cuándo hay impuestos? Obtenido de Agencia Tributaria http://www.agenciatributaria.es/AEAT.educacion/Profesores_VT6_es_ES.ht

BBVA. (1 de Julio de 2018). Clasificación de empresas según su tamaño. Obtenido de BBVA: https://www.bbva.es/general/finanzas-vistazo/empresas/clasificacion-de-empresaspor-tamano/index.jsp

Beltrán, S. F. (2014). Estimación de la Recaudación Potencial en el Impuesto al Trabajo y a los Ingresos al Capital. http://www.redalyc.org/articulo.oa?id=423739497005.

Berliri, A. (2009). Principios de Derecho Tributario. España: Editorial de Derecho Financiero.

CIIU, D. d. (2014). Clasificación Industrial Internacional Uniforme de todas las actividades económicas (CIIU). Nueva York: Informes estadísticos No. 4/Rev. 4. Obtenido de https://unstats.un.org/unsd/publication/seriesm/seriesm_4rev4s.pdf

Congreso Nacional. (12 de 11 de 1997). Servicio de rentas internas. Obtenido de LEY ORGÁNICA DE RÉGIMEN TRIBUTARIO INTERNO: http://www.sri.gob.ec/de/ice

Coronel, T., \& Farez, M. (2010). Gestión del talento humano en base a competencias laborales requeridas aplicadas a la empresa Duramas Cía. Ltda. En C. T., \& F. M., Gestión del talento humano en base a competencias laborales requeridas aplicadas a la empresa Duramas Cía. Ltda (pág. 15). Cuenca: Universidad de Cuenca, Facultad de Ciencias Económicas y Administrativas.

Delfín \& Díaz, F. L. (2014). Importancia y análisis del desarrollo empresarial. Bogotá: Universitaria Konrad Lorenz. doi:http://dx.doi.org/10.14482/pege.40.8810

Delfin, F., \& Acosta, M. (2016). Importancia y análisis del desarrollo empresarial. redalyc, 125.

Domínguez, P. R. (2014). Introducción a la gestión empresarial. Fundamentos teóricos y aplicaciones prácticas. En P. R. Domínguez, Introducción a la gestión empresarial. Fundamentos teóricos y aplicaciones prácticas (pág. 16). España: Instituto Europeo de Gestión Empresarial.

Ekos Negocios. (2014). PYMES, contribución clave de la economía. Ecuador: Ekos Negocios. Obtenido de https://www.ekosnegocios.com/negocios/verArticuloContenido.aspx?idArt=1229

EKOS, R. (01 de 11 de 2017). ekosnegocios. Recuperado el 19 de 11 de 2018, de ekosnegocios: http://www.ekosnegocios.com/negocios/verArticuloContenido.aspx ?idArt=9813

Facultad de Psicología de la UNAM. (02 de agosto de 2010). MÉTODOS DE 
INVESTIGACIÓN. Obtenido de http://www.psicol.unam.mx/Investigacion2/: http://www.psicol.unam.mx/Investigacion2/pdf/METO2F.pdf

Faustos. (06 de agosto de 2016). Revistas líderes. Obtenido de Revista lideres: www.revistalideres.ec

Flor, D., \& Acosta, M. (2016). Importancia y análisis del desarrollo empresarial. redalyc, 2-3. Flores, Z. E. (2004). Elementos de Finanzas Públicas. México: Porrúa.

Giler Zerna. (2018). Desconocimiento de los Impuestos y su incidencia en la Cultura Tributaria en el Ecuador. Ecuador: Repositorio Dspace. Obtenido de http://repositorio.unemi.edu.ec/xmlui/handle/123456789/4021

Gómez, G. J. (11 de 12 de 2010). La historia de los impuestos. Obtenido de eumed: http://www.eumed.net/librosgratis/2011a/912/Historia\%20de\%20los\%20impuestos.ht $\mathrm{m}$

González, O. V. (2017). Gestión de Capital Humano. Cuba: Universidad Agraria de la Habana.

Grinvalds, K. (18 de 01 de 2018). emprendepyme.net. Obtenido de emprendepyme.net: https://www.emprendepyme.net/que-es-la-gestion-empresarial.html

Hernández, Fernández, \& Baptista. (2006). Metodología de la investigación. México: McGraw Hill.

Herrero, M. (2015). Estrategias educativas para el desarrollo de una cultura tributaria en América Latina. Caracas: Experiencias y líneas de acción: CLAD.

IDE Business School. (12 de 11 de 2015). IDE Business School. Obtenido de Breve historia de los impuestos: http://investiga.ide.edu.ec/index.php/impuestos-gobiernoyeconomiaialiados-o-enemigos

INEC. $(1$ de febrero de 2014). INEC. Obtenido de INEC.EC: http://www.ecuadorencifras.gob.ec/documentos/web-

inec/Estadisticas_Economicas/DirectorioEmpresas/Empresas_2014/Principales_Resul tados_DIEE_2014.pdf

INEC. $(1$ de febrero de 2017). INEC. Obtenido de INEC.EC: http://www.ecuadorencifras.gob.ec/documentos/web-

inec/Estadisticas_Economicas/DirectorioEmpresas/Empresas_2014/Principales_Resul tados_DIEE_2014.pdf

Játiva, K., \& Ortega, O. (2016). Impuestos y su impacto en el desarrollo de las PYMES en el Ecuador. En K. Játiva, \& O. R., Impuestos y su impacto en el desarrollo de las PYMES en el Ecuador (pág. 95). Ecuador.

Koontz, H., \& Weirich, H. (s.f.). Una perspectiva Global, 12ª edición, En “Administración” (pág. 25). México: Mc Graw Hill.

López, A. C. (2012). La cultura tributaria en un grupo de actividad económica informal en la provincia de Pichincha. Quito: Universidad Politécnica Salesiana.

Ministerio de comercio exterior. (12 de 11 de 2016). Ministerio de comercio exterior. Obtenido de

Resolución

006-2016:

http://www.comercioexterior.gob.ec/wpcontent/uploads/downloads/2016/04/Resoluci on-006-2016.pdf

Morales. (04 de febrero de 2007). fundamentos de la investigación documental y la de campo. Obtenido de https://www.google.com.ec/url? sa=t\&rct=j\&q=\&esrc=s\&source=web\&cd=5\&cad=rj a\&uact=8\&ved=0ahUKEwjlx8nc_LnKAhXC5SYKHabzBWwQFgg1MAQ\&url=http $\% 3 \mathrm{~A} \% 2 \mathrm{~F} \% 2 \mathrm{Ffiles}$.ecouna.webnode.es\%2F200000023-

2c4f02d476\%2FFUNDAMENTOS\%2520DE\%2520INVESTIGACI\%25C3\%2592N 
Onofre, Z. R., Aguirre, R. C., \& Murillo, T. G. (2017). La cultura tributaria y su incidencia en la recaudación de los tributos en el Cantón Babahoyo, Provincia de los Ríos. Dom. Cien., ISSN: 2477-8818.

Padilla, M., Quispe, A., Rivera, N. D., Hernández, A., \& Moreno, G. K. (2018). El emprendimiento como gestión empresarial para un desarrollo sostenible. scielo, 1.

Pardo, C., \& Díaz, O. (2014). Desarrollo del talento humano como factor clave para el desarrollo organizacional, una visión desde los líderes de gestión humana en empresas de Bogotá D.C. ScienceDirect, 18.

Pardo, E. (2014). Gestión Estratégica para Recursos. España: Fundación Universitaria Konrad Lorenz. Obtenido de https://doi.org/10.1016/S2215-910X(14)70018-7

Prado, C. R. (2016). La efectividad de los mecanismos tecnológicos para recaudación tributaria como instrumento para reducir la evasión fiscal. Guayaquil: Escuela Superior del Litoral.

Revista Negocios. (2011). Análisis económico y social por la aplicación de impuestos. NAG Gonzales.

Samuelson, P. S. (2016). Macroeconomía. México: McGraw-Hill. doi: ISBN 84-481-0648-2

Secretaría Nacional de Planificación y Desarrollo. (12 de 11 de 2013). Secretaría Nacional de Planificación y Desarrollo. Obtenido de plan nacional para el buen vivir: http://documentos.senplades.gob.ec/Plan\%20Nacional\%20Buen\%20Vivir\%

Servicio de Rentas Internas. (12 de 11 de 2015). Servicio de Rentas Interna. Obtenido de Impuesto a la renta: http://www.sri.gob.ec/de/impuesto-a-la-renta

Servicio de Rentas Internas. (2015). Tasa Impositiva Ecuador 2015. Quito: http://www.sri.gob.ec/web/guest/167.

Servicio de Rentas Internas. (12 de 02 de 2019). Servicio de Rentas Interna. Obtenido de Impuesto a la renta: http://www.sri.gob.ec/de/impuesto-a-la-renta

Siñani, J. (2012). Presión Tributaria Departamental e Informalidad. Revista Perspectivas.

Tapia, E. (2018). Lenin Moreno anuncia cinco incentivos económicos al empezar su segundo año de Gobierno. El Comercio, 1.

Trecet, J. (2015). Impuestos indirectos. Financialred, 1.

Vargas, N. G., Mera, B., \& Flores, B. S. (2017). Reglamento -Código de la Producción. Quito: Herrera Cía. Ltda. 3ra Edición.

Vázquez, O., \& Zenea, M. (2017). La gestión de capital humano por competencias laborales de los profesores universitarios con un enfoque estratégico. Cofin Habana, 11.

Vélez, F. (01 de 11 de 2014). SlideShare. Recuperado el 15 de 11 de 2018, de Gestión empresarial ii: https://es.slideshare.net/garridocaballero/gestin-empresarial-ii

Vidal, F. M., Caraguay, V. M., \& Salcedo, M. V. (2017). "Carga tributaria y recaudación fiscal en el ecuador: un análisis mediante la curva de laffer. UTMACH: ISSN 2588 - 056X.

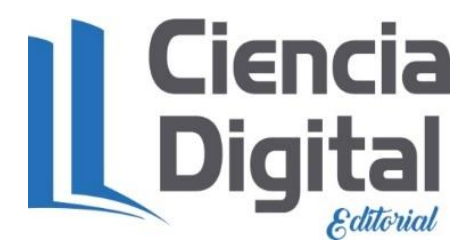


PARA CITAR EL ARTÍCULO INDEXADO.

Flores Guamán, J., \& Padilla Martínez, M. (2019). Efectos económicos de la aplicación de impuestos directos e indirectos a las PYMES en la provincia de Tungurahua periodo 2014 - 2017. Visionario Digital,3(3), 24-48. https://doi.org/10.33262/visionariodigital.v3i3.606

\section{Ciencia}

El artículo que se publica es de exclusiva responsabilidad de los autores y no necesariamente reflejan el pensamiento de la Revista Visionario Digital.

El artículo queda en propiedad de la revista y, por tanto, su publicación parcial y/o total en otro medio tiene que ser autorizado por el director de la Revista Visionario Digital.
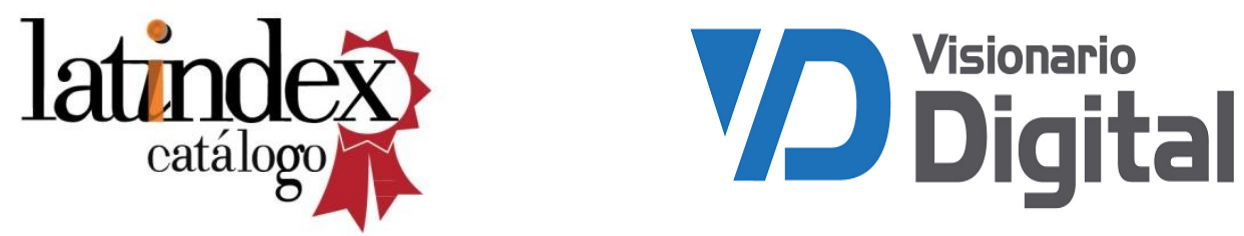